\title{
Height in relation to dementia death: individual participant meta-analysis of 18 UK prospective cohort studies
}

Tom C. Russ, Mika Kivimäki, John M. Starr, Emmanuel Stamatakis and G. David Batty

\section{Background}

That risk factors measured in middle age may not fully explain future dementia risk implicates exposures acting earlier in life. Height may capture early-life illness, adversity, nutrition and psychosocial stress.

\section{Aims \\ To investigate the little-explored association between height and dementia death. \\ Method \\ Individual participant meta-analysis using 18 prospective general population cohort studies with identical methodologies (1994-2008; $n=181800)$.}

\section{Results}

Mean follow-up of 9.8 years gave rise to 426 and 667

dementia deaths in men and women respectively. The mean heights were $174.4 \mathrm{~cm}$ (s.d. $=7.3$ ) for men and $161.0 \mathrm{~cm}$ (s.d. =6.8) for women. In analyses taking into account multiple covariates, increasing height was related to lower rates of death from dementia in a dose-response pattern $(P \leqslant 0.01$ for trend). There was evidence of a differential effect by gender ( $P=0.016$ for interaction). Thus, the association observed in men (hazard ratio per s.d. decrease in height $1.24,95 \% \mathrm{Cl} 1.11-1.39)$ was markedly stronger than that apparent in women $(\mathrm{HR}=1.13,95 \% \mathrm{Cl} 1.03-1.24)$.

\section{Conclusions}

Early-life circumstances, indexed by adult height, may influence later dementia risk.

\section{Declaration of interest}

None.
With no current disease-modifying treatment for dementia, there is a pressing need to understand the aetiology of this condition with a view to delaying or preventing its onset. It is evident that known risk factors for dementia measured in middle age - hypertension, smoking, obesity and dyslipidaemia - do not seem to fully explain the occurrence of the disease. ${ }^{1-3}$ This has prompted some recent interest in the pre-adult origins of dementia. ${ }^{4}$ In the absence of cohort studies beginning in childhood with a sufficiently long period of follow-up to allow enough individuals to develop dementia in later life, investigators have relied on the distant recall of early-life risk factors, such as early parental death and childhood socioeconomic adversity. ${ }^{5-7}$ This raises concerns regarding reporting bias. ${ }^{8}$ Height may be more useful in this context. It is regarded as a marker of early-life illness, adversity, nutrition and psychosocial stress, ${ }^{9}$ environmental characteristics that influence brain development which may then affect dementia risk. ${ }^{10}$ Importantly, although there may be some loss of height in late life, it remains relatively stable from early to late adulthood and may therefore be a reliable marker of early-life exposures.

Findings from a small series of cohort studies indicate that lower physical stature is associated with elevated rates of dementia, ${ }^{11}$ and this effect may be different in men and women. ${ }^{12}$ However, in general, studies have been underpowered. The fact that the few extant studies are small in scale hampers examination of the height-dementia association in detail, for example in exploring threshold effects and planned subgroup analyses of the height-dementia relationship, including by gender. Accordingly, in this study we add to the limited evidence base by presenting an individual participant meta-analysis of 18 large, prospective, general population-based cohort studies. Individual participant meta-analysis has several advantages relative to the more commonly used literature-based approach: the inclusion of unpublished data, so minimising publication bias; a more precise estimate of associations between risk marker and disease than in lesser-powered single studies; reliable information on the 'shape' of the association; and a consistent approach to statistical control for plausible covariates. To the best of our knowledge, this is the largest study to date to examine the association between height and dementia and the first individual participant meta-analysis on the topic.

\section{Method}

Participants were taken from the Health Survey for England (HSE) for the years 1994-2008 and the Scottish Health Survey (SHS) for 1995, 1998 and 2003. Both surveys were representative, general population-based health examination studies sampling individuals living in households in the UK. ${ }^{13,14}$ From 1994 to 2008, 18 independent, cross-sectional studies with almost identical methodologies were conducted on either an annual (HSE) or an occasional (SHS) basis. The majority of study members $(88 \%)$ consented to mortality surveillance by linkage to the UK National Health Service death register. The near-identical nature of these surveys, allied with this recent retrospective and prospective linkage of study members to mortality records, makes possible a unique individual participant meta-analysis. Study participants gave full informed consent, and ethical approval for data collection was granted by the London research ethics council or the local research ethics councils.

Participants were visited by a trained interviewer who measured height and weight, and subsequently by a nurse who collected biomedical data. The interviewer measured height once with shoes removed (to the nearest millimetre) with the informant stretching to maximum height. The head was positioned in the Frankfort plane and a portable stadiometer with a sliding plate, a base plate and three connecting rods marked with a metric measuring scale was used. Weight was measured using electronic digital scales and, with height, allowed computation of body mass index in $\mathrm{kg} / \mathrm{m}^{2}$. Information on occupational social class was 
collected during the interview and coded according to the Registrar General's classification (professional, intermediate, skilled non-manual, skilled manual, part skilled and unskilled), a standard approach in the UK. ${ }^{15}$ Age in years on leaving full-time education was recorded as $<15,15,16,17,18,>18$, 'never went to school' and 'still in full-time education'. Ethnic group was based on self-report. Smoking status was classified as never a regular smoker, ex-smoker and smoker with daily consumption recorded. During the interview participants were asked whether or not they suffered from a longstanding illness. At the nurse visit, systolic blood pressure was measured with the mean of the second and third readings used in the present analyses. Blood was drawn to measure serum cholesterol.

\section{Ascertainment of dementia}

Causes of death (up to ten) recorded on certificates were coded using the International Classification of Diseases (ICD-9 and ICD-10). ${ }^{16,17}$ Any mention of dementia death was identified using codes 290.0 to $290.4,294.9,331.0$ to 331.2 and 331.9 for ICD-9 and codes F00, F01, F03, F09, G30 and G31 for ICD-10. In preliminary analyses we examined the impact of using broad definitions of dementia (any mention of dementia) or narrow definitions (where dementia was the underlying cause of death). Since results were essentially the same but the broader definition resulted in greater power (online Table DS1) we used 'any mention' of dementia in all survival analyses.

\section{Statistical analysis}

After ascertaining that the proportional hazards assumption had not been violated we used Cox proportional hazards models to compute study-specific hazard ratios with accompanying 95\% confidence intervals for the association between height and dementia death. ${ }^{18}$ We report hazard ratios for height quartiles with the tallest group as the referent. With preliminary analyses revealing that the height-dementia association was linear, we also report hazard ratios per 1 standard deviation reduction in height (1 s.d. $=6.8 \mathrm{~cm}$ in women, $7.3 \mathrm{~cm}$ in men). Heterogeneity in the effect estimates between studies was examined using the $I^{2}$ statistic, which indicates the proportion of the total variation in the estimates that is due to between-studies variation. Preliminary analyses revealed that $I^{2}$ ranged between $0 \%$ and $58 \%$, so we pooled the study-specific effect estimates and their standard errors in random effects meta-analyses, an approach we have taken in previous analyses. ${ }^{15,19,20}$ Calendar time (months) from survey date was the underlying time scale; for participants who did not die from dementia, data were censored at the end of March 2011.

Data for men and women were analysed separately. Models were initially adjusted for age and then additionally for a series of covariates comprising occupational social class, educational attainment, ethnic group, body mass index, smoking status and self-reported longstanding illness. We also controlled for birth year to allow for secular increases in height. ${ }^{21}$ Data for blood pressure and serum cholesterol were not collected in every survey (see online Table DS2) and were additionally missing for some participants during the survey years when data collection took place; these data therefore only feature in subgroup analyses. We compared the effects of controlling for different confounding and mediating variables on the magnitude of the association by examining the change in hazard ratio rather than a change in significance level. ${ }^{22}$ Individuals with data missing for one or more variables and those with no missing data were compared using Student's $t$-test for continuous variables and $\chi^{2}$-tests for categorical variables. All analyses were conducted using $\mathrm{R}$ for Mac version 3.0.2. The reporting of our analyses conforms to the Strengthening the Reporting of Observational Studies in Epidemiology (STROBE) statement. ${ }^{23}$

\section{Results}

Figure 1 shows the derivation of the analytical sample. Excluding 1840 individuals missing consent data and 1365 missing survival time reduced the sample size from 222829 to 219624 . With other exclusions (survey participants who declined mortality follow-up or whose height was not measured) the final analytic sample was 181800 (55\% female). The mean age at baseline was 45.0 years (s.d. =18.0); among those who died the mean age at death was 55.8 years $($ s.d. $=17.5)$. Further details of the individual cohort studies and individuals who did and did not consent to mortality follow-up are provided in online Tables DS2 and DS3 respectively. Baseline characteristics of the sample categorised by height quartile are shown in Table 1. Increasing height was generally associated with a more favourable risk factor profile in both men and women: taller study members were younger, from higher socioeconomic backgrounds, had slightly lower body mass index, a lower prevalence of longstanding illness and lower levels of blood pressure and serum cholesterol. Taller men were also less likely to smoke, but the reverse was true of women. Of the 17553 deaths recorded during a mean follow-up of 9.8 years (s.d.=4.4), 1093 were dementia-related. Figure 2 shows the age-adjusted hazard ratios for the association between 1 s.d. decrease in height and dementia death in men and women for each cohort study. Overall, there was a $26 \%$ increased risk of dementia death per s.d. decrease in height in men $(\mathrm{HR}=1.26,95 \%$ CI $1.14-1.40 ; P<0.001$ for trend) and $10 \%$ increased risk of dementia death in women (HR $=1.10,95 \%$ CI $1.01-1.19 ; P=0.031$ for trend). Table 2 shows the association between height quartile and dementia death after

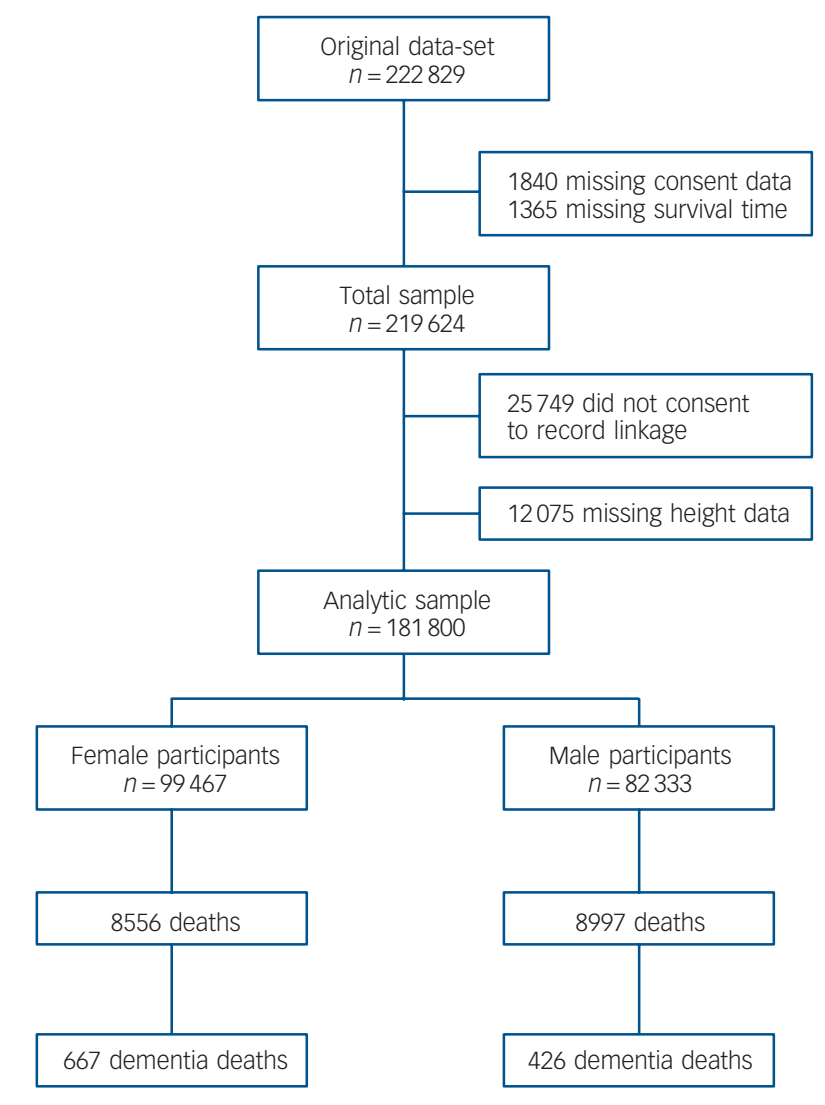

Fig. 1 Flow chart of participants from initial pooled sample through to analytic sample showing subsequent mortality. 


\begin{tabular}{|c|c|c|c|c|c|}
\hline & \multicolumn{5}{|c|}{ Height quartile $e^{a, b}$} \\
\hline & $\mathrm{Q}_{1}$ (shortest) & $\mathrm{Q}_{2}$ & $\mathrm{Q}_{3}$ & $\mathrm{Q}_{4}$ & Total $n^{c}$ \\
\hline \multicolumn{6}{|l|}{ Men } \\
\hline$n$ & 20398 & 20890 & 20667 & 20376 & 82333 \\
\hline Age, years: mean (s.d.) & $53.6(18.8)$ & $47.4(17.6)$ & $43.5(16.7)$ & $39.5(15.0)$ & 82333 \\
\hline Non-manual social class, \% & 38.6 & 45.5 & 51.1 & 56.6 & 79251 \\
\hline Left school >16 years, $\%$ & 51.9 & 64.6 & 73.4 & 81.9 & 82290 \\
\hline White British, \% & 85.3 & 90.4 & 92.8 & 94.7 & 82333 \\
\hline BMI, kg/m²: mean (s.d.) & $26.9(4.4)$ & $26.9(4.2)$ & $26.6(4.2)$ & $26.2(4.0)$ & 80281 \\
\hline Never smoker, \% & 38.8 & 41.5 & 44.5 & 48.1 & 81972 \\
\hline Longstanding illness, \% & 50.6 & 44.4 & 38.9 & 36.8 & 82314 \\
\hline Systolic blood pressure, mmHg: mean (s.d.) & $137.9(19.8)$ & $135.1(17.2)$ & $133.6(15.8)$ & $132.4(14.5)$ & 53255 \\
\hline Serum cholesterol, mmol/l: mean (s.d.) & $5.7(1.2)$ & $5.7(1.2)$ & $5.5(1.1)$ & $5.4(1.1)$ & 27017 \\
\hline \multicolumn{6}{|l|}{ Women } \\
\hline$n$ & 24443 & 25266 & 24971 & 24787 & 99467 \\
\hline Age, years: mean (s.d.) & $54.2(19.6)$ & $47.2(17.6)$ & $43.4(16.6)$ & $39.3(14.8)$ & 99467 \\
\hline Non-manual social class, \% & 54.8 & 62.5 & 66.8 & 71.5 & 92695 \\
\hline Left school >16 years, \% & 51.2 & 64.7 & 72.6 & 82.3 & 99410 \\
\hline White British, \% & 85.8 & 90.9 & 93.0 & 94.5 & 99467 \\
\hline BMI, kg/m²: mean (s.d.) & $27.4(5.6)$ & $26.8(5.3)$ & $26.2(5.2)$ & $25.6(4.9)$ & 94147 \\
\hline Never smoker, \% & 57.0 & 53.7 & 52.1 & 52.0 & 99130 \\
\hline Longstanding illness, \% & 51.3 & 43.4 & 40.5 & 36.1 & 99450 \\
\hline systolic blood pressure, mmHg: mean (s.d.) & $135.4(23.7)$ & $130.4(20.5)$ & $127.1(18.7)$ & $124.7(16.3)$ & 63874 \\
\hline Serum cholesterol, mmol/l: mean (s.d.) & $5.9(1.3)$ & $5.8(1.2)$ & $5.6(1.2)$ & $5.4(1.1)$ & 31519 \\
\hline
\end{tabular}

adjustment for covariables. In age- adjusted analyses there was a dose-response association in both men and women such that lower physical stature was associated with raised dementia mortality rates. There was also some evidence of weaker associations in women than men: a formal test for effect modification was statistically significant at conventional levels (multivariable adjusted model $P=0.016$ for interaction). Adjusting for measures of socioeconomic status had a modest attenuating effect on this association.

\section{Sensitivity and subgroup analyses}

We conducted a series of sensitivity and subgroup analyses to test the robustness of our results. Data were missing for one or more

\begin{tabular}{|c|c|c|c|c|}
\hline $\begin{array}{l}\text { (a) } \\
\text { Study }\end{array}$ & Participants & $\begin{array}{c}\text { Dementia } \\
\text { deaths }\end{array}$ & $\mathrm{HR}(95 \% \mathrm{Cl})$ & \\
\hline HSE1994 & 6677 & 53 & $1.24(0.97-1.59)$ & \\
\hline HSE1995 & 6572 & 67 & $1.33(1.01-1.77)$ & \\
\hline HSE1996 & 6828 & 56 & $1.42(1.04-1.94)$ & \\
\hline HSE1997 & 3588 & 25 & $1.23(0.79-1.90)$ & \\
\hline HSE1998 & 6518 & 48 & $1.08(0.79-1.48)$ & \\
\hline HSE1999 & 5412 & 19 & $0.61(0.36-1.02)$ & \\
\hline HSE2O00 & 3143 & 26 & $1.27(0.84-1.90)$ & \\
\hline HSE2001 & 5903 & 32 & $1.46(1.00-2.15)$ & \\
\hline HSE2O02 & 3879 & 14 & $1.31(0.74-2.31)$ & \\
\hline HSE2O03 & 5495 & 21 & $1.06(0.64-1.75)$ & \\
\hline HSE2O04 & 3856 & 3 & $0.37(0.11-1.30)-$ & - \\
\hline HSE2O05 & 3411 & 17 & $1.66(0.99-2.78)$ & \\
\hline HSE2O06 & 4888 & 4 & $1.70(0.55-5.31)$ & \\
\hline HSE2O07 & 2321 & 2 & $0.49(0.11-2.18) \longrightarrow$ & \\
\hline HSE2008 & 4871 & 1 & $3.91(0.21-1.69)$ & $\rightarrow$ \\
\hline SHS1995 & 2928 & 8 & $1.19(0.57-2.51)$ & \\
\hline SHS1998 & 3273 & 17 & $2.12(1.20-3.75)$ & $\longrightarrow$ \\
\hline SHS2O03 & 2770 & 13 & $1.52(0.82-2.80)$ & $\longrightarrow$ \\
\hline Summary $\left(I^{2}=0.0 \%\right)$ & 82333 & 426 & $1.26(1.14-1.40)$ & 0 \\
\hline
\end{tabular}

variables in 34833 individuals (18.0\%). Individuals with complete data for all variables are compared with those with any missing data in online Table DS4. Although there were some differences in study characteristics, when we computed age-adjusted hazard ratios using a non-missing sample it replicated the main findings. Additionally, dropping deaths occurring in the first 5 years of follow-up to explore reverse causality did not alter our conclusions (Table 2).

\section{Discussion}

Our main finding was a dose-response association between shorter height and risk of subsequent dementia death. There was some (b) Study

HSE1994 HSE1995 HSE1996

HSE1997

HSE1998

HSE1999

HSE2000

HSE2001

HSE2002

HSE2003

HSE2004

HSE2005

HSE2006

HSE2007

HSE2008

SHS1995

SHS1998

SHS2003

Summary $\left(I^{2}=0.0 \%\right) \quad 99467$

deaths HR $(95 \% \mathrm{Cl})$

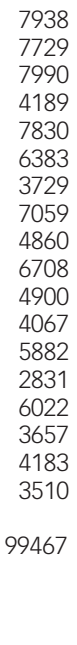

$1.02(0.83-1.24)$ $1.22(0.98-1.54)$ $1.15(0.91-1.47)$ $1.14(0.83-1.58)$ $1.08(0.86-1.37)$ $0.85(0.57-1.28)$ $0.86(0.64-1.15)$ $1.19(0.85-1.68)$ $1.00(0.58-1.72)$ $0.81(0.48-1.35)$ $1.42(0.84-2.42)$ $0.99(0.52-1.88)$ $1.19(0.69-2.03)$ $1.73(0.37-8.08)$ $1.93(0.26-14.13)$ $2.66(0.81-8.72)$ $1.46(0.93-2.29)$ $1.46(0.75-2.82)$

667

$1.10(1.01-1.19)$

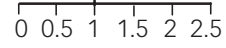
Hazard ratio

Fig. 2 Number of participants, total mortality and deaths from dementia categorised by year. Also shown are age- and gender-adjusted hazard ratios (HRS) of dementia death per standard deviation lower height according to survey year for (a) men and (b) women: individual participant meta-analysis of 18 cohort studies from the Health Survey for England (HSE) and the Scottish Health Survey (SHS). 
Table 2 Hazard ratios for the association between height quartile and dementia-related death

\begin{tabular}{|c|c|c|c|c|c|c|c|c|}
\hline & \multirow[b]{2}{*}{$\begin{array}{l}\text { Dementia } \\
\text { deaths }\end{array}$} & \multirow[b]{2}{*}{$n$} & \multicolumn{5}{|c|}{ Hazard ratio $(95 \% \mathrm{Cl})$} & \multirow[b]{2}{*}{$P_{\text {trend }}$} \\
\hline & & & $\begin{array}{c}\mathrm{Q}_{4}{ }^{\mathrm{a}} \\
\text { (tallest) }\end{array}$ & $\mathrm{Q}_{3}$ & $\mathrm{Q}_{2}$ & $\mathrm{Q}_{1}$ & $\begin{array}{c}\text { Per s.d. } \\
\text { disadvantage }\end{array}$ & \\
\hline \multicolumn{9}{|l|}{ Men } \\
\hline Age-adjusted (basic model) & 426 & 82333 & 1 (Ref.) & $1.27(0.75-2.16)$ & $1.32(0.80-2.17)$ & $1.67(1.05-2.67)$ & $1.26(1.14-1.40)$ & $<0.001$ \\
\hline+ Social class & 425 & 79251 & 1 & $1.22(0.72-2.09)$ & $1.23(0.74-2.03)$ & $1.52(0.95-2.45)$ & $1.21(1.09-1.34)$ & $<0.001$ \\
\hline + Educational attainment & 425 & 82290 & 1 & $1.20(0.71-2.05)$ & $1.25(0.76-2.06)$ & $1.56(0.97-2.50)$ & $1.24(1.11-1.37)$ & $<0.001$ \\
\hline + Ethnic group & 426 & 82333 & 1 & $1.29(0.76-2.20)$ & $1.34(0.81-2.22)$ & $1.73(1.08-2.77)$ & $1.27(1.14-1.41)$ & $<0.001$ \\
\hline + Body mass index & 413 & 80281 & 1 & $1.24(0.73-2.13)$ & $1.30(0.79-2.16)$ & $1.70(1.06-2.72)$ & $1.29(1.16-1.44)$ & $<0.001$ \\
\hline + Smoking status & 426 & 81972 & 1 & $1.25(0.71-2.13)$ & $1.28(0.77-2.11)$ & $1.59(0.99-2.55)$ & $1.25(1.13-1.39)$ & $<0.001$ \\
\hline + Longstanding illness & 426 & 82314 & 1 & $1.26(0.74-2.15)$ & $1.30(0.79-2.15)$ & $1.68(1.05-2.68)$ & $1.26(1.14-1.40)$ & $<0.001$ \\
\hline + Systolic blood pressure ${ }^{c}$ & 275 & 49030 & 1 & $1.06(0.51-2.19)$ & $1.22(0.60-2.49)$ & $1.42(0.76-2.67)$ & $1.30(1.14-1.49)$ & $<0.001$ \\
\hline+ Serum cholesterol ${ }^{\mathrm{C}}$ & 130 & 23911 & 1 & $0.59(0.22-1.59)$ & $1.03(0.26-4.01)$ & $1.11(0.50-2.46)$ & $1.28(1.03-1.58)$ & 0.025 \\
\hline Multivariable-adjusted $^{\mathrm{d}}$ & 411 & 76927 & 1 & $1.15(0.67-1.98)$ & $1.18(0.71-1.96)$ & $1.50(0.93-2.43)$ & $1.24(1.11-1.39)$ & $<0.001$ \\
\hline \multicolumn{9}{|l|}{ Early deaths excluded } \\
\hline (multivariable-adjusted) ${ }^{\mathrm{d}, \mathrm{e}}$ & 310 & 65455 & 1 & $1.15(0.64-2.07)$ & $1.36(0.77-2.40)$ & $1.44(0.85-2.45)$ & $1.27(1.12-1.45)$ & $<0.001$ \\
\hline Non-missing sample (age-adjusted) & 411 & 76927 & 1 & $1.20(0.70-2.05)$ & $1.26(0.76-2.08)$ & $1.65(1.03-2.63)$ & $1.27(1.14-1.41)$ & $<0.001$ \\
\hline \multicolumn{9}{|l|}{ Women } \\
\hline Age-adjusted (basic model) & 667 & 99467 & 1 (Ref.) & $1.40(0.90-2.19)$ & $1.04(0.66-1.62)$ & $1.22(0.76-1.97)$ & $1.10(1.01-1.19)$ & 0.031 \\
\hline+ Social class & 617 & 86994 & 1 & $1.37(0.87-2.16)$ & $0.96(0.59-1.57)$ & $1.19(0.73-1.95)$ & $1.11(1.01-1.19)$ & 0.026 \\
\hline + Educational attainment & 667 & 99410 & 1 & $1.33(0.85-2.08)$ & $0.96(0.62-1.50)$ & $1.11(0.70-1.77)$ & $1.07(0.98-1.16)$ & 0.143 \\
\hline + Ethnic group & 667 & 99467 & 1 & $1.40(0.90-2.19)$ & $1.04(0.66-1.64)$ & $1.25(0.78-2.00)$ & $1.11(1.02-1.20)$ & 0.018 \\
\hline + Body mass index & 651 & 94147 & 1 & $1.56(0.98-2.48)$ & $1.19(0.75-1.90)$ & $1.49(0.91-2.44)$ & $1.15(1.05-1.25)$ & 0.002 \\
\hline + Smoking status & 666 & 99130 & 1 & $1.41(0.90-2.20)$ & $1.04(0.67-1.62)$ & $1.23(0.78-1.96)$ & $1.10(1.01-1.19)$ & 0.032 \\
\hline + Longstanding illness & 667 & 99450 & 1 & $1.43(0.92-2.24)$ & $1.05(0.68-1.63)$ & $1.25(0.78-2.00)$ & $1.10(1.01-1.19)$ & 0.033 \\
\hline + Systolic blood pressure ${ }^{c}$ & 431 & 62684 & 1 & $1.55(0.87-2.78)$ & $1.10(0.63-1.90)$ & $1.41(0.85-2.34)$ & $1.09(0.98-1.21)$ & 0.118 \\
\hline+ Serum cholesterol ${ }^{\mathrm{C}}$ & 195 & 27696 & 1 & $1.67(0.75-3.74)$ & $1.44(0.66-3.16)$ & $1.60(0.75-3.39)$ & $1.05(0.90-1.22)$ & 0.542 \\
\hline Multivariable-adjusted $^{d}$ & 601 & $82115^{f}$ & 1 & $1.48(0.92-2.39)$ & $1.06(0.64-1.74)$ & $1.35(0.80-2.28)$ & $1.13(1.03-1.24)$ & 0.011 \\
\hline Early deaths excluded & & & & & & & & \\
\hline (multivariable-adjusted) $)^{\mathrm{d}, \mathrm{e}}$ & 495 & 74221 & 1 & $1.39(0.81-2.39)$ & $0.95(0.49-1.85)$ & $1.05(0.45-2.49)$ & $1.10(0.99-1.22)$ & 0.063 \\
\hline Non-missing sample (age-adjusted) & 601 & $82115^{f}$ & 1 & $1.50(0.93-2.42)$ & $1.08(0.63-1.85)$ & $1.38(0.79-2.39)$ & $1.14(1.05-1.25)$ & 0.003 \\
\hline \multicolumn{9}{|c|}{$\begin{array}{l}\text { Q, quartile; Ref., referent. } \\
\text { a. Gender-specific height quartiles were calculated using the following cut-points: men } 179.3 \mathrm{~cm}, 174.4 \mathrm{~cm}, 169.6 \mathrm{~cm} \text {; women } 165.5 \mathrm{~cm}, 161.1 \mathrm{~cm}, 156.5 \mathrm{~cm} \text {. } \\
\text { b. Calculated using gender-specific standard deviations: men } 7.3 \mathrm{~cm} \text {; women } 6.8 \mathrm{~cm} \text {. } \\
\text { c. Data were only available for a subsample and therefore these covariates were not included in the multivariable model. } \\
\text { d. Model adjusted for age, occupational social class, educational attainment, self-reported ethnic group, body mass index, smoking status, self-reported longstanding illness and } \\
\text { year of birth. } \\
\text { e. Deaths occurring within the first } 5 \text { years of follow-up were dropped. No event occurred in the HSE 2006-2008 surveys so these were excluded. } \\
\text { f. No event occurred in HSE } 2008 \text { so this survey was excluded from this model. }\end{array}$} \\
\hline
\end{tabular}

suggestion that this relationship was stronger in men. It was robust to adjustment for a series of covariates including socioeconomic status and extant illness. That we were also able to demonstrate known associations between shorter stature and an increased risk of cardiovascular disease (age- and gender-adjusted HR per s.d. decrease in height $1.11,95 \%$ CI 1.07-1.16) but a decreased risk of cancer $(\mathrm{HR}=0.94,95 \%$ CI $0.89-0.98)$ in this meta-analysis gives us confidence in the more novel heightdementia association. ${ }^{24-26}$

\section{Mechanisms of effect}

The fact that the observed association between height and dementia was apparently robust to the adjustment of a series of covariables leads to speculation regarding the mechanisms that might generate this relationship. Clearly height in itself is not a risk factor for dementia; rather, the exposures it captures may be key. In addition to genetic factors, a recent review of epidemiological studies highlighted various socio-environmental determinants of adult height, including early-life socioeconomic circumstances, childhood nutrition, chronic psychosocial stress and chronic illness. ${ }^{21}$ Insulin growth factor IGF-1 has been linked to cerebral amyloid, ${ }^{27}$ and, similarly, growth hormone levels, which are correlated with height and also linked to hippocampal function and cognition. Thus, IGF-1 might have a role in the association between height and dementia death. ${ }^{4}$ Furthermore, important exposures may also act in utero, but research linking birth characteristics to dementia is sparse. There is also the possibility that height might be a measure of cognitive and functional reserve, ${ }^{28}$ and a positive association has been demonstrated between height and intelligence, ${ }^{29}$ which is also related to dementia risk, particularly vascular dementia. ${ }^{10,30}$ A further possibility is a common genotype determining height and dementia risk. Average height in populations has generally increased in a secular fashion over the past century, with a marked increase in the first quarter of the 20th century (Fig. 3). The fact that there has been a general improvement in early-life circumstances over the same period supports the hypothesis that height captures something of early-life experience relevant to later dementia risk, particularly in the light of recent studies suggesting that the prevalence of dementia might have decreased in recent years. ${ }^{31}$ Given the large sample size in our study the smaller effect identified in women is unlikely to be explained by statistical instability. One possibility is that physical stature in women is less sensitive to living conditions. That diminishing secular increases in female height have been observed in recent years provides some support for this. ${ }^{21}$

\section{Comparison with other literature}

The published research on the association between stature and dementia risk is detailed in online Table DS5. Our study is the first to examine the association between stature and dementia mortality. However, for comparison, research reporting on the association with clinical dementia is discussed here. In a Medicare study of the association between knee height and arm span and 
dementia in four areas of the USA, 480 participants developed dementia over a mean 5.4 year follow-up. ${ }^{12}$ Both measures of shorter stature were associated with a higher risk of dementia in women, but only arm span was associated with dementia risk in men. A study in Israel only of men demonstrated an odds ratio of dementia (309 cases) comparing the tallest and shortest height quartiles of 0.51 (95\% CI 0.35-0.74) after adjusting for age, socioeconomic status and region of birth. ${ }^{11}$ A study of Japanese Americans in Washington, USA, as part of the Ni-Hon-Sea Project - mainly focusing on head circumference - similarly commented that individuals developing dementia (59 incident cases) were shorter than those who did not go on to develop the condition. However, this was not examined in detail. ${ }^{32}$

Cross-sectional studies also add to the evidence for a link between height and dementia. A study of an older Korean population ( $n=746,110$ dementia cases) found an association between shorter leg length and demispan and dementia after adjusting for age and education. ${ }^{33}$ When men and women were considered separately results were statistically significant only in women, but since only $41 \%$ of the sample were men this might have been a result of reduced power. Another Korean study ( $n=235$, with 46 dementia cases) found an association between decreased height and increased dementia risk (age- and genderadjusted HR per $\mathrm{cm}$ decrease 1.09, 95\% CI 1.05-1.14), which was attenuated with further adjustment for education, smoking, alcohol, pulse pressure, hypertension and type 2 diabetes mellitus $(\mathrm{HR}=1.03$, 95\% CI $0.97-1.11) .^{28}$ The HARMONY study of Swedish twins conducted a case-control analysis of 310 people with dementia and 3063 controls. $^{34}$ They found that being more than 1 s.d. below the gender-specific mean in height was associated with an odds ratio of dementia of 1.57 (95\% CI
1.11-2.22). A case-control study from the USA found a lower risk of Alzheimer's disease in women, adjusted for age and education, but not men. ${ }^{35}$ However, when they stratified by APOE $\varepsilon 4$ status they found this association only in women without that allele $(\mathrm{OR}=0.88$, 95\% CI 0.80-0.97). A further Korean study found an association, only in women, between leg length and Alzheimer's disease, after adjustment for age, rural residence in childhood and education. ${ }^{36}$

There is growing evidence - from studies of variable quality and statistical power - that shorter body stature, measured in a variety of ways, is associated with an increased risk of cognitive decline and dementia in men and women. A number of studies have reported a dose-response association, ${ }^{11,12,35,37}$ but the majority have treated height as a continuous measure without demonstrating a linear relationship. ${ }^{28,32,33,36,38,39}$ We were able to demonstrate a statistically significant, dose-response association between decreasing height and dementia death. One prospective study and two cross-sectional studies showed a stronger association between height and dementia in women than in men. ${ }^{12,33,36}$ We found the converse. It is possible that this disagreement relates to power or to the different outcomes: the studies referred to above used a clinical diagnosis of dementia as their outcome, as opposed to dementia-related death used in our study. Details of dementia incidence were not available for our included cohort studies. We are not aware of any studies directly comparing risk factors for dementia incidence and dementia-related mortality.

\section{Limitations}

Our large sample was representative of the general population in the UK and was well characterised in terms of baseline

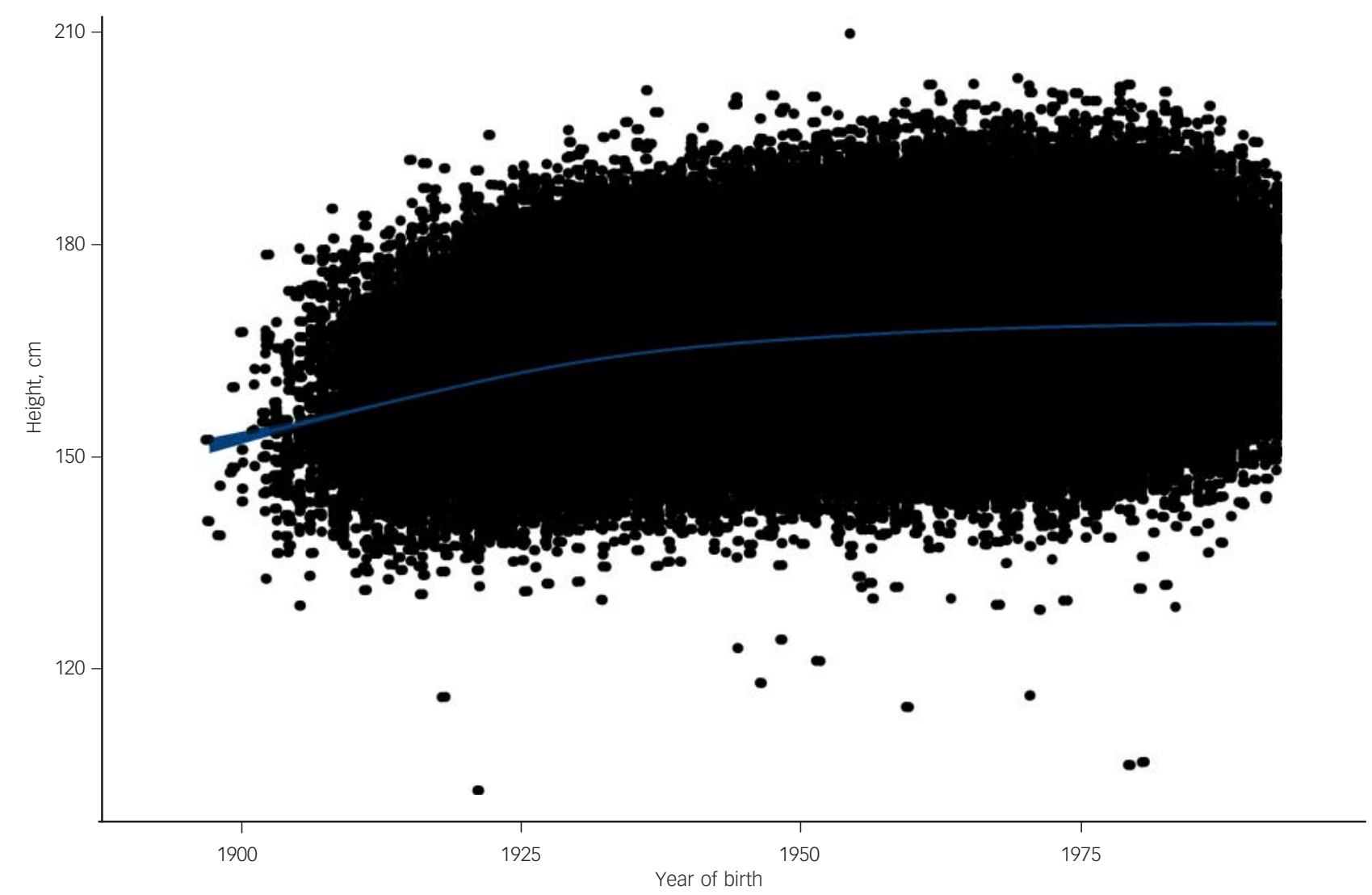

Fig. 3 Secular trend (with 95\% confidence interval) in height according to birth year: 18 cohort studies from the Health Survey for England and Scottish Health Survey. 
characteristics. This provided sufficient power to allow genderspecific analyses and allowed us to explore the role of a series of explanatory factors. Crucially, this study is well characterised for socioeconomic status (educational attainment and occupational social class) which is a key confounding variable given its association with dementia and height. This notwithstanding, the data also have their limitations. The number of dementia-related deaths in this study is likely to have been affected by the unavoidable problems of underdiagnosis of dementia in the community, ${ }^{40}$ underrecording of dementia on death certificates and diagnoses being inaccurately coded. Non-recording of dementia on death certificates has been highlighted as an important issue but this seems to be improving. A recent study identified that $71.5 \%$ of a clinic sample diagnosed with probable Alzheimer's disease had dementia correctly recorded on their death certificate. ${ }^{41}$ There was no association in that sample between correct dementia certification and area deprivation or premorbid IQ score estimated by the National Adult Reading Test (unpublished results available from the authors on request), suggesting that individuals reported as having dementia on their death certificate are representative of the population of people with diagnosed dementia in the community, at least in terms of intelligence and level of deprivation.

\section{Future research directions}

Ideally, a long-term longitudinal study with adult height and relevant covariates measured in early life could be analysed over decades of follow-up to investigate this association in more detail, including information on parental height in order to take genetic determinants of height into account. In the absence of such a study, a more detailed investigation of just what it is that height is capturing that is associated with later dementia risk would allow more accurate forecasts of dementia incidence to be calculated.

\section{Implications of the study}

We have demonstrated a dose-response association between height and later dementia death which was robust to adjustment for a series of covariates. We propose the hypothesis that the mechanism driving this association may be early-life circumstances and thus add to the growing evidence of the role of pre-adult factors in later dementia risk. Furthermore, public health policies should continue on a broad front, including pre-school education, breakfast clubs, improved parenting schemes and vaccination programmes.

Tom C. Russ, PhD, MRCPsych, Alzheimer Scotland Dementia Research Centre University of Edinburgh, Scottish Dementia Clinical Research Network, National Health Service (NHS) Scotland, Centre for Cognitive Ageing and Cognitive Epidemiology, and Division of Psychiatry, University of Edinburgh; Mika Kivimäki, PhD, Department of Epidemiology and Public Health, University College London; John M. Starr, PhD, FRCPEd, Alzheimer Scotland Dementia Research Centre, University of Edinburgh, Scottish Dementia Clinical Research Network, NHS Scotland, Centre for Cognitive Ageing and Cognitive Epidemiology, University of Edinburgh, UK; Emmanuel Stamatakis, PhD, Charles Perkins Centre, and Exercise and Sport Sciences, Faculty of Health Sciences, University of Sydney, Australia; G. David Batty, PhD, Alzheime Scotland Dementia Research Centre, University of Edinburgh, Centre for Cognitive Ageing and Cognitive Epidemiology, University of Edinburgh, and Department of Epidemiology and Public Health, University College London, UK

Correspondence: Dr Tom C. Russ, Division of Psychiatry, Kennedy Tower, Roya Edinburgh Hospital, Morningside Terrace, Edinburgh EH10 5HF, UK. Email: tc.russ@ed.ac.uk

First received 6 Dec 2013, final revision 4 Jun 2014, accepted 6 Jun 2014

\section{Funding}

The Health Survey for England is part of a programme of surveys commissioned by the UK National Health Service (NHS) Information Centre for Health and Social Care, and carried out since 1994 by the Joint Health Surveys Unit of the National Centre for Social Research and the Department of Epidemiology and Public Health at University College London. Currently employed by the University of Edinburgh and the UK NHS, T.C.R. was supported by Alzheimer Scotland during the preparation of this manuscript. T.C.R., J.M.S. and G.D.B. are members of both the Alzheimer Scotland Dementia Research Centre funded by Alzheimer scotland and the University of Edinburgh Centre for Cognitive Ageing and Cognitive Epidemiology, part of the cross-council Lifelong Health and Wellbeing Initiative (G0700704/84698). Funding from the Biotechnology and Biological Sciences Research Council, the Engineering and Physical Sciences Research Council, the Economic and Social Research Council (ESRC) and the UK Medical Research council (MRC) is gratefully acknowledged. E.S. is funded by a National Institute for Health Research career development fellowship and M.K. is supported by the MRC (K013351), the US National Institutes of Health (R01HL036310, R01AG034454) and a professorial fellowship from the ESRC.

\section{References}

1 Breteler MMB. Early life circumstances and late life Alzheimer's disease. Epidemiology 2001; 12: 378-9.

2 Andel R, Crowe M, Pedersen NL, Fratiglioni L, Johansson B, Gatz M. Physical exercise at midlife and risk of dementia three decades later: a populationbased study of Swedish twins. J Gerontol A Biol Sci Med Sci 2008; 63: 62-6.

3 Tyas SL, White LR, Petrovitch H, Webster Ross G, Foley DJ, Heimovitz HK, et al. Mid-life smoking and late-life dementia: the Honolulu-Asia Aging Study. Neurobiol Aging 2003; 24: 589-96.

4 Borenstein $\mathrm{AR}$, Copenhaver $\mathrm{Cl}$, Mortimer JA. Early-life risk factors for Alzheimer disease. Alzheimer Dis Assoc Disord 2006; 20: 63-72.

5 Persson G, Skoog I. A prospective population study of psychosocial risk factors for late onset dementia. Int J Geriatr Psychiatry 1998; 11: 15-22.

6 Norton MC, Østbye T, Smith KR, Munger RG, Tschanz JT. Early parental death and late-life dementia risk: findings from the Cache County Study. Age Ageing 2009; 38: 340-3.

7 Whalley LI, Staff RT, Murray AD, Deary IJ, Starr JM. Genetic and environmental factors in late onset dementia: possible role for early parental death. Int J Geriatr Psychiatry 2013; 28: 75-81.

8 Batty GD, Lawlor DA, Macintyre S, Clark H, Leon DA. Accuracy of adults' recall of childhood social class: findings from the Aberdeen children of the 1950s study. J Epidemiol Community Health 2005; 59: 898-903.

9 Batty GD, Shipley MJ, Langenberg C, Marmot MD, Smith GD. Adult height in relation to mortality from 14 cancer sites in men in London (UK): evidence from the original Whitehall study. Ann Oncol 2006; 17: 157-66.

10 Whalley L, Starr J, Athawes R, Hunter D, Pattie A, Deary I. Childhood mental ability and dementia. Neurology 2000; 55: 1455-9.

11 Beeri MS, Davidson M, Silverman JM, Noy S, Schmeidler J, Goldbourt U. Relationship between body height and dementia. Am J Geriatr Psychiatry 2005; 13: 116

12 Huang T, Carlson M, Fitzpatrick A, Kuller L, Fried L, Zandi P. Knee height and arm span: a reflection of early life environment and risk of dementia. Neurology 2008; 70: 1818-26.

13 Mindell J, Biddulph JP, Hirani V, Stamatakis E, Craig R, Nunn S, et al. Cohort profile: the Health Survey for England. Int J Epidemiol 2012; 41: 1585-93.

14 Gray L, Batty GD, Craig P, Stewart C, Whyte B, Finlayson A, et al. Cohort profile: the Scottish Health Surveys cohort. Int J Epidemiol 2009; 39: 345-50.

15 Russ TC, Stamatakis E, Hamer M, Starr JM, Kivimäki M, Batty GD. Socioeconomic status as a risk factor for dementia death: individual participant meta-analysis of 86508 men and women from the UK. $\mathrm{Br} J$ Psychiatry 2013; 203: 10-7.

16 World Health Organization. International Statistical Classification of Diseases and Related Health Problems (ICD-9). WHO, 1978.

17 World Health Organization. International Statistical Classification of Diseases and Related Health Problems (ICD-10). WHO, 1992.

18 Cox DR. Regression models and life-tables. J Roy Stat Soc B 1972; 34: 187-220.

19 Russ TC, Hamer M, Stamatakis E, Starr JM, Batty GD, Kivimaki M. Does the Framingham cardiovascular disease risk score also have predictive utility for dementia death? An individual participant meta-analysis of 11,887 men and women. Atherosclerosis 2013; 228: 256-8.

20 Russ TC, Stamatakis E, Hamer M, Starr JM, Kivimaki M, Batty GD. Association between psychological distress and mortality: individual participant pooled analysis of 10 prospective cohort studies. BMJ 2012; 345: e4933.

21 Batty GD, Shipley MJ, Gunnell D, Huxley R, Kivimaki M, Woodward M, et al. Height, wealth, and health: an overview with new data from three longitudinal studies. Econ Hum Biol 2009; 7: 137-52.

22 Batty GD, Der G, Macintyre S, Deary IJ. Does IQ explain socioeconomic inequalities in health? Evidence from a population based cohort study in the west of Scotland. BMJ 2006; 332: 580-4. 
23 Von Elm E, Altman D, Egger M, Pocock SJ, Gotzsche PC, Vandenbroucke JP. Strengthening the reporting of observational studies in epidemiology (STROBE) statement: guidelines for reporting observational studies. BMJ 2007; 335: 806-8.

24 Paajanen TA, Oksala NKJ, Kuukasjarvi P, Karhunen PJ. Short stature is associated with coronary heart disease: a systematic review of the literature and a meta-analysis. Eur Heart J 2010; 31: 1802-9.

25 Emerging Risk Factors Collaboration. Adult height and the risk of causespecific death and vascular morbidity in 1 million people: individual participant meta-analysis. Int J Epidemiol 2012; 41: 1419-33.

26 Gunnell D, Okasha M, Smith GD, Oliver S, Sandhu J, Holly J. Height, leg length and cancer risk: a systematic review. Epidemiol Rev 2001; 23: 313-42.

27 Giuffrida ML, Tomasello F, Caraci F, Chiechio S, Nicoletti F, Copani A. Beta-amyloid monomer and insulin/IGF-1 signaling in Alzheimer's disease. Mol Neurobiol 2012; 46: 605-13.

28 Jeong SK, Kim JM, Kweon SS, Shin MH, Seo MW, Kim YH. Does arm length indicate cognitive and functional reserve? Int J Geriatr Psychiatry 2005; 20 406-12.

29 Starr JM, Kilgour A, Pattie A, Gow A, Bates TC, Deary IJ. Height and intelligence in the Lothian Birth Cohort 1921: a longitudinal study. Age Ageing 2010; 39: 272-5.

30 McGurn B, Deary IJ, Starr JM. Childhood cognitive ability and risk of lateonset Alzheimer and vascular dementia. Neurology 2008; 71: 1051-6.

31 Matthews FE, Arthur A, Barnes LE, Bond J, Jagger C, Robinson L, et al. A two-decade comparison of prevalence of dementia in individuals aged 65 years and older from three geographical areas of England: results of the Cognitive Function and Ageing Study I and II. Lancet 2013; 382: 1405-12.

32 Borenstein Graves A, Mortimer JA, Bowen J, McCormick WC, McCurry SM, Schellenberg GD, et al. Head circumference and incident Alzheimer's disease: modification by apolipoprotein E. Neurology 2001; 57: 1453-60.
33 Kim J, Stewart R, Shin I, Yoon J. Limb length and dementia in an older Korean population. J Neurol Neurosurg Psychiatry 2003; 74: 427-32.

34 Gatz M, Mortimer JA, Fratiglioni L, Johansson B, Berg S, Reynolds CA, et al. Potentially modifiable risk factors for dementia in identical twins. Alzheimers Dement 2006; 2: 110-7.

35 Petot GJ, Vega U, Traore F, Fritsch T, Debanne SM, Friedland RP, et al. Height and Alzheimer's disease: findings from a case-control study. J Alzheimers Dis 2007; 11: 337-41.

36 Kim JM, Stewart R, Shin IS, Kim SW, Yang SJ, Yoon JS. Associations between head circumference, leg length and dementia in a Korean population. Int J Geriatr Psychiatry 2008; 23: 41-8.

37 Mak Z, Kim JM, Stewart R. Leg length, cognitive impairment and cognitive decline in an African-Caribbean population. Int J Geriatr Psychiatry 2006; 21: $266-72$

38 Abbott RD, White LR, Ross GW, Petrovitch H, Masaki KH, Snowdon DA, et al. Height as a marker of childhood development and late-life cognitive function: the Honolulu-Asia Aging Study. Pediatrics 1998; 102: 602-9.

39 Umegaki $H$, limuro $S$, Kaneko $T$, Araki A, Sakurai $T$, Ohashi $Y$, et al. Factors associated with lower Mini Mental State Examination scores in elderly Japanese diabetes mellitus patients. Neurobiol Aging 2008; 29 : 1022-6.

40 Sampson EL, Blanchard MR, Jones L, Tookman A, King M. Dementia in the acute hospital: prospective cohort study of prevalence and mortality. Br J Psychiatry 2009; 195: 61-6.

41 Russ TC, Batty GD, Starr JM. Cognitive and behavioural predictors of survival in Alzheimer disease: results from a sample of treated patients in a tertiaryreferral memory clinic. Int J Geriatr Psych 2012; 27: 844-53.

क EXTRA 